\title{
Lessons From A Dominican Republic Field Study
}

Michael M. Gunter, Jr., Rollins College, USA

\begin{abstract}
Utilizing student-centered pedagogy, this case study explores an increasingly prominent and instructive addition to traditional academic coursework - the field study experience. This is particularly true in the arena of environmental education where students learn best by experiencing environmental problems first-hand and then interacting with those involved. From a teaching methods and styles perspective, then, this paper espouses a mix of experiential and active learning strategies. The central message of this essay, however, is curriculum-based, to report on an engaging two-week field trip to examine sustainable development in the Dominican Republic. From this report, the analysis highlights student feedback mechanisms, such as formal class journals, traditional course evaluations, and informal oral consultations with students, both during and after the field study as the basis to offer suggestions more broadly on how to design and implement a field study course.
\end{abstract}

Keywords: Active learning, experiential learning, Dominican Republic, field study, sustainable development

\section{INTRODUCTION}

he case examines twelve students who took a semester-long course on sustainable development in the Dominican Republic at Rollins College during Spring 2002. Following this course, these same students traveled to the Dominican Republic for a series of visits with governmental and non-governmental entities in May 2002. Students met informally with these leaders in a seminar-style environment and then visited the sights of these discussions afterwards, seeing with their own eyes the obstacles to sustainable development that many Dominicans face in their day-to-day lives. This type of course is one of several that Rollins College is currently developing in conjunction with a newly created minor in sustainable development. This minor is the product of a unique partnership between the departments of environmental studies and international business and demonstrative of a college-wide commitment to global, interdisciplinary, and experiential undergraduate education.

Thanks to an anonymous grant, moreover, student travel scholarships are available so that "students who would otherwise be unable to participate... [are able to] experience first-hand the economic context of environmental issues in the developing world." Similar courses with field study components focus upon Costa Rica, Dominica, Ecuador's Galapagos Islands, Peru, and Singapore, as well as Vietnam. ${ }^{2}$ Each of these courses, along with the class on the Dominican Republic, was designed with three central objectives in mind:

1. to provide an intensive international experience for students

2. to expressly tie this real world international experience to academic theory discussed in the classroom

3. to organize all this around the central question of what obstacles exist to sustainable development and how they may be overcome

\footnotetext{
${ }^{1}$ Rollins College. "Sustainable Development and Transnational Corporations: A New Program at Rollins." 1 July 2002, <http://www.Rollins.edu/susdev/desc.html $>$.

2 Additional information on the Sustainable Development and the Environment program at Rollins College is available at the website: http://www.Rollins.edu/susdev/index.html.
} 
Taking these objectives into consideration, this work examines student feedback with the hope of improving future such practica. The following pages first describe the actual course, including both the spring semester and field study components. The discussion then proceeds to address obstacles encountered, as well as ameliorating variables, before offering an overall assessment in closing.

\section{DESCRIPTION OF THE COURSE}

\section{Spring Semester Component}

Before embarking on the field study itself, students enrolled in a traditional semester long course worth four credit hours. Over the course of sixteen weeks, this class emphasized the need to better understand sustainable development by taking an in-depth look at the Dominican Republic. We spent the first several weeks discussing the highly controversial and deeply ingrained value judgments that surround the term sustainable development. Students gained a grasp of just how politically charged this debate is before uncovering the emerging general consensus as to the objective of sustainable development, epitomized by the 1987 Brundtland Report definition as that which utilizes the interest of the earth's natural resources without encroaching upon its capital. ${ }^{3}$ Students also learned that just exactly how this process is carried out remains hotly contested. That is, the precise political steps for policy implementation remain fuzzy to date. As such, sustainable development has come to represent the larger domain of political discussion that surrounds the environment in the developing world (although the developed world certainly cannot be excluded either) and economic development more generally.

After this first stage, our course then examined the Dominican Republic's history, society, and culture. Here students gained a greater appreciation for the racism which pervades the island of Hispaniola, an island that the Dominican Republic shares with the poorest country in the Western hemisphere and one of the most impoverished states in the world - Haiti. ${ }^{4}$ Students also learned about continued significance of past military engagements with Haiti as well as the fact that the Dominican Republic first gained its independence not from Spain but from Haiti in 1844, after twenty-two years of rule. And even with this initial independence, fear of future Haitian invasions was so great that the Dominican Republic actually requested Spanish colonial rule again in 1861. Spanish colonial rule was no better the second time around. It ended in 1865 with a bloody War of Restoration between Dominican nationalists and Spanish sympathizers. Many believe this underlying fear of Haiti continues to guide Dominican politics to this day.

In this political vein, students also learned about the extent to which an authoritarian past still casts its shadow over the state. An array of typical Latin American strongmen dot the $19^{\text {th }}$ and $20^{\text {th }}$ century political landscape, but the most infamous of those assumed power with more votes than there were eligible voters in 1930. Rising to power by coup, dictator Rafael Trujillo hit his island nation even harder than the hurricane that crashed upon its coast that same year. He ruled the Dominican Republic as his personal fiefdom for some thirty-two years, until his assassination in late May $1961 .^{5}$ At one time his immediate family controlled as much as eighty percent of the state's industrial production. ${ }^{6}$ Even forty years after his death this legacy is still felt despite the democratic system in place today. For instance, the 1996 elections were the first that lacked any complaints of fraud. Trujillo also instituted a number of both public and private practices that reinforced a national consciousness of race. Most despicable among a litany of actions was his October 1937 massacre of some 15,000 to 17,000 Haitians along the Dominican border. This heinous act was part of the stated national policy of Dominicanization. Trujillo also sought to "lighten" the population by encouraging the resettlement of a number of refugees from Europe and Japan. Not surprisingly, on a personal level, Trujillo himself was concerned with his own lack of whiteness, often applying pancake makeup to lighten his skin.

\footnotetext{
${ }^{3}$ World Commission on Environment and Development. (1987). Our Common Future. Oxford: Oxford University Press.

${ }^{4}$ Interestingly, this sharing of an island by two different states is unique in the Caribbean. The only other example is the division of Saint-Martin and Saint Maarten between the French and Dutch, respectively.

${ }^{5}$ Several students were able to see authentic artifacts of this assassination and other aspects of Trujillo's life on exhibit at the Museum on the Dominican Man in Santo Domingo.

${ }^{6}$ Howard, David. (1999). Dominican Republic In Focus: A Guide to the People, Politics and Culture. New York: Interlink Books, 23.
} 
After a five week period emphasizing such history, society, and culture, a third and final stage expressly tied the first two together, outlining how history, society, and culture in the Dominican Republic pertain to sustainable development today. In this section we emphasized sustainable solutions in the Dominican Republic, challenging students to rethink management of both the economy and the environment. Of particular focus was the lack of political stability in the country. Echoing comments from a number of authors such as David Howard ${ }^{7}$ and Jennifer Elliott, ${ }^{8}$ students targeted political credibility and legitimacy as essential to any hope for future sustainable development. As one student noted in her journal:

Nothing will change and the DR will not ever truly develop without eventual political stability throughout the island. $(J W)$

\section{Field Study Component}

The field study component itself was an additional, required two-credit practica that involved spending just under two weeks in the Dominican Republic. It was required along with the spring course as the two were listed as co-requisites in our college catalogue. ${ }^{9}$ Students were required to make logistical and financial arrangements early in the spring semester for this May component of the course, with an application and preliminary deposit deadline of Jan. $22^{\text {nd }}$. (Total fees were due soon after on Feb. $1^{\text {st }}$.) Scholarship funds were available for travel to the Dominican Republic, and, thanks to the aforementioned outside grant, a majority of the class received partial funding.

Students saw a significant portion of the country in a short period of time. Occupying the eastern $2 / 3$ rds of Hispaniola, the Dominican Republic is about the size of New Hampshire and Vermont combined and home to roughly 8.5 million people. We traveled from the major metropolitan area of Santo Domingo, which holds almost three million of the eight and a half million general population, to the far southwestern outskirts of the country along the Haitian border. Other stops included the heartland of the fertile Cibao region, the picturesque Samana peninsula, and the trendy tourist mecca in Puerto Plata.

Beginning with our initial day and a half in the capital city of Santo Domingo, the oldest Western hemisphere city with European colonial ties, students were exposed to sights, sounds, scents, and tastes they had never encountered before. In Santo Domingo students participated in a seminar and discussion by Dr. Manuel Vargas, Director General of the Presidential Plan Against Poverty and attended a celebration in the shantytown of Maquiteria, a poor neighborhood near Parque Mirador del Este in capital city of Santo Domingo. Here citizens were honoring the government for paving over an alley between their homes. The Government had recently funded construction of a cement path along a steeply inclined alley, and the community was celebrating the completion of this project, a project which at least one woman in attendance had pursued for forty years. It connected homes form one end of the hillside to the paved road about one thousand yards above. As one student commented in her journal:

These people were celebrating the fact that "El Plan Presidencial contra la Bobreza," which Dr. Vargas is in charge of, built and paved a small alley that crossed through a couple of houses. This alley was very necessary because every time it rained, it was both dangerous and almost impossible for the people to reach their houses...All the people were extremely excited, and I realized how many insignificant things such as an alley can make such a HUGE difference for other people. We definitely take too many things for granted. (CH)

In subsequent days our group traveled along the southwestern coast to the Barahona area, a part of the country rife with unemployment. Students saw the full extent of this unemployment first hand. As one student noted in her journal:

\footnotetext{
${ }^{7}$ Howard, David. (2001). Colouring the Nation: Race and Ethnicity in the Dominican Republic. Oxford: Lynne Rienner Publishers.

${ }^{8}$ Elliott, Jennifer. (1999). An Introduction to Sustainable Development. NY: Routledge.

${ }^{9}$ One student did end up dropping out of the field study just days before we embarked. She lost a substantial deposit as her penalty.
} 
There were a lot of really hard things to face and see on this trip. There were disturbing social problems we observed from environmental degradation, abject poverty, high scourge of AIDS, deadly contaminated or polluted water, to high rates of domestic abuse, early adolescent pregnancy and an abundance of adolescent (8 to 15 yearold) prostitution. (MD)

Another group of students went out on their own in Barahona to visit with local families along the dirt road by our hotel. Interacting on this personal level in the homes of some of the very poorest Dominicans made a lasting impression. Students were awed by the poor living conditions yet generous hearts of those they met. For instance, villagers shared homemade lemonade and the rare gemstone larimar with our students. Larimar, said to be a gift from Atlantis, comes in a variety of colors from pale blue-green to deep aqua blue. The bluer it is, the rarer it is. And any larimar is indeed a rare gemstone as it is found in only one area in the world, inside the crater of an extinct volcano in the Sierra Baoruco of the southwestern Dominican Republic. ${ }^{10}$

While in this region of the country, we spoke with the leaders of an eco-tourism school in Neiba, attempted to enter the Haitian border just outside the garrison town of Jimani, and stopped to take in the splendor of Lago Enriquillo, a magnificent saltwater lake whose waters are three times more salty than the sea. A national park since 1974, the area supports a range of flora and fauna, including a large crocodile population imported in the 1930s from the United States for an ill-fated attempt to generate tourism. Enriquillo takes its name from a legendary Taino rebel chief who organized the native population against the Spanish in the early $16^{\text {th }}$ century, even periodically descending from the mountains to liberate plantation slaves. ${ }^{11}$ Lago Enriquillo, a thirteen-mile long inland saltwater lake (and also the Caribbean's lowest point at 130 feet below sea level) was a welcome stop for our group, particularly following our disappointment at the Haitian border and a long drive through the barren southwestern landscape.

After a couple days in the southwest our class headed northeast to the center of the country where we visited the Centro ILAC water purification project in Comedero Abajo and then spent a brief evening at the allinclusive resort Club on the Green in Playa Dorada along the northern coast. Both of these stops made notable impressions on the class. As one student wrote in their field study journal:

The biggest impact [for me was the] women at the water purification center. It was so simple and practical. AND we got to hear first hand about the problem of lack of communication as a threat to this program. (DC)

That same student also labeled the evening stop as the low point of his trip, pointing out the lack of local population involvement in the all-inclusive resort model and the relative isolation that guest's experience from the local culture as a result. The next morning we set out for the far eastern coast, specifically the ecological showcase known as the Samana peninsula, where students engaged in an eco-tourist trip to the impressive 165-foot waterfall La Cascada. Following a weekend in Samana, we then spent an afternoon seeing the fertile Cibao valley and spoke with the Governor of Moca before spending our last three and a half days in Santo Domingo with a series of meetings involving contacts of the Director General of the Presidential Plan Against Poverty.

\section{OBSTACLES ENCOUNTERED}

No trip is complete without its share of obstacles. Our twelve-day stint in the Dominican Republic was no exception. Traveler's diarrhea quickly made its way through the troops, making its presence felt in each participant at one time or another - some more than others. We also had an auto accident at the beginning of the second week of the trip, hitting a horse along a rural road in the Samana peninsula. We were told the horse was not owned by anyone, but a number of men were trying to catch it when it bolted across the street in an effort to escape. No one other than the horse was hurt physically, but the incident made a lasting impression on several students and set a somber mood for the rest of the day. The accident also demonstrated how important is to be both prepared and flexible in such a situation. We were covered with accidental insurance and also had funds available to compensate the potential horse owners and fix the dent in our van.

\footnotetext{
${ }^{10}$ Jayvo Designs. "The Story of Larimar." 7 Oct. $2002<$ http://www.jayvodesigns.com/larimar/story.htm $>$.

${ }^{11}$ Pons, Frank Moya. (1998). The Dominican Republic: A National History. Princeton, N.J.: Markus Wiener Publishers, 41.
} 
Two more obstacles revolved around the students. For one, there is the inevitable challenge of mitigating group dynamics amongst a group of nineteen, twenty, and twenty-one year-olds. Personality conflicts often arise, particularly as you spend a considerable amount of time together throughout the twelve-day period. Nowhere was this more obvious than while in transit on some of the longer trips. Being corralled in a van for several hours was not any easier when your last meal is not settling particularly well, or as more often was the case, settling all too well as it rushed through your system. As one student notes:

I have two regrets this trip: one, not being able to speak Spanish; and two, not being able to give my full attention to some of the other speakers because we showed up after three hours in the van. (DC)

And there is always the alluring siren of nightlife and alcohol to confront. A number of safety issues as well as basic legal liability dictate concerns here, not to mention the simple fact that over-indulgences can severely handicap plans for the following day. Thanks to a mature core in our group of students, and perhaps aided by a tiring daily schedule, these obstacles were minimized throughout the trip.

An important aside involving safety also deserves mention here. Outside of Santo Domingo we stayed at several all-inclusive resorts. While the all-inclusive option did keep students from venturing out to test the city life in the evenings, thus eliminating potential safety concerns, some more humble lodging exposure would have been a valuable complement to the three resort visits. Logistical adjustments in Caboller Abojo unfortunately forced a change in our original plans to provide this experience at the water filter distribution center. And, in fact, several students expressed frustration about staying in all-inclusive resorts. By definition these resorts are unsustainable and draw a stark contrast to the eco-tourism industry, an industry in its infant stages in the Dominican Republic. One student even compared the Hotel Bahia in Samana to the hotel featured in The Shining and noted of all-inclusive resorts in general, "I'm pissed that we are actually staying here (at the inclusive resort of Puerto Plata)." Fortunately, that same student was awed the following day with our local emersion in a journey to the 165 -foot waterfall at El Limon, which he called a "magical place of humbling proportions." Perhaps just as exciting as La Cascada for many of the students was the one-mile trip itself aboard locally-owned mules and horses. It also gave students a true example of eco-tourism in that the profits went directly into local pockets while our presence did little damage ecologically. ${ }^{12}$

Another frustration expressed by the students was the lack of time available to make unplanned stops as well as periodic changes in the schedule. The stops we were able to make, though, clearly made strong impressions on the students. A typical comment was one such as this:

The class was great, and I learned so much. But the field study was irreplaceable. To actually speak to Dominicans and Haitians about what they experience in their everyday life was amazing. $(C W)$

Another student concurred, referring to the bateyes and prostitution interview visits:

Today was a very awakening day, as this entire trip has been. It amazes me how differently something can affect you in person as opposed to mere words and stories. $(\mathrm{CH})$

In fact, perhaps the most memorable stop for many students was in the bateyes just north of San Pedro de Macoris. These bateyes are amongst the poorest in the nation and often draw comparisons to old slavery huts in the ante-bellum South of the United States. They feature Haitian immigrants, both legal and illegal, that work for just a few hundred Dominican pesos a week - but can go for as long as six months without being paid. Despite being the one with a machete, one Haitian we met off a dirt road was much more leery of our group than we were him. In a mixture of his marginal Spanish and native tongue Creole, we were able to gather that he feared we would ask for his immigration papers and report him to authorities as an illegal immigrant.

\footnotetext{
${ }^{12}$ Honey, Martha S. “Treading Lightly? Eco-tourism's Impact on the Environment," Environment, 41(5) (June 1999), 4-9. 28-
} 33. 


\section{AMELIORATING VARIABLES}

Beyond being both organized and flexible, this case study demonstrated that seven conditions increase the likelihood for a successful field study abroad. These include student caliber, student language capabilities, institutional mechanisms within the college itself, linkage or co-requisite status of the field study with another traditional course, contacts within the country being visited, student accountability, and just plain luck. Each of these in turn supports the overarching theme that successful field studies are both well organized and flexible at the same time. Perhaps the best place to start in thinking about creating the infrastructure to support this objective is to examine the students themselves. As noted earlier, we were fortunate to have a diverse mix of students, almost all of which displayed a high degree of intellectual curiosity. A number of factors contributed to this good fortune. While a degree of luck cannot be entirely discounted, the nature of the course - specifically its subject matter and connection to a new minor at the college - attracted a number of impressive students. This, combined with the availability of scholarships, thanks to funding set aside in a generous grant, enabled a spectrum of economic and social backgrounds to participate. Too often field studies abroad involve expenses that exclude the less fortunate students. These scholarships removed that barrier.

Another characteristic involving the student is the ability to speak some degree of the local language. Language capabilities, not surprisingly, clearly enhanced the experience. Two of our twelve students were native speakers. A third student was virtually fluent. And two more students had more than one year of Spanish training, growing increasingly confident as the days passed. That meant almost half of our class had some degree of speaking ability. Future field studies abroad, if logistically feasible, should attempt to raise this ratio even more. Perhaps a prerequisite could be one semester of the language spoken at the field study location, or as a bare minimum requirement, two weeks of language preparation during the semester before leaving.

Several institutional mechanisms also helped boost the caliber of student. Students were required to make a deposit for the field study early in the co-requisite spring semester course. Once they became aware of this requirement, several less sincere students opted out of the course during the first week of classes. The administration, furthermore, was very supportive in both keeping the per-student cost of the trip low (much of which was also possible only due to the hard work of my colleague Pedro Pequeno) and in allowing a smaller than normal class size. While we originally capped our course at eighteen, just below the standard upper level cap of twenty at Rollins, this number quickly dropped to a more manageable number of thirteen in the first week of classes.

Another obvious characteristic to emphasize is the fact that this field study was not a stand-alone course. It was only available to those students that completed the regular spring semester course. This turned out to be a fruitful combination, as one student noted in her journal:

I have gained so much from taking the class with the combination of the twelve-day travel lab. This has helped me become more observant and sensitive to different world perspectives - and more analytical. (MD)

Listing these two offerings as co-requisites enabled us to prepare the students with a considerable amount of background knowledge that improved the quality of the field study experience immeasurably. Students were not just happy-go-lucky tourists tasting the local cuisine and testing the warm Caribbean waters. While they certainly enjoyed both of these offerings, students had a vested interest in the course and completed a degree of historical and cultural preparation that enabled them to better appreciate what they saw first hand. And, of course, nothing can replace seeing something yourself. Student after student reiterated this fact as the premier strength of the trip. For example, on student said:

Seeing poverty first hand does not compare to hearing or reading about it. Visiting with the locals right outside their homes had quite an impact on me; it helped me internalize something we've been studying and made it relevant and real. The need for social change is greater than I was able to discern from any reading materials. (MC)

And another student: 
Learning about the Dominican Republic and Haiti from a classroom in Winter Park, Florida, is very different from experiencing the culture first hand. I could have never imagined the magnitude of the social issues that this country faces without seeing, experiencing, and feeling it for myself. At one time or another I think our group covered every social issue that we learned about in class on our twelve-day trip to the Dominican Republic. And seeing for yourself gives you a whole different perspective to the theory that you may have learned for a test, in lecture, or while doing a paper. $(\mathrm{JW})$

Still another fundamental condition is the presence of knowledgeable, trusted, and influential local contacts. The more contacts you have in the country, the better. And having at least one contact within the government is virtually immeasurable. We were fortunate in our course to have not one but two Rollins faculty native to the Dominican Republic. Each of these faculty members, moreover, has extensive contacts in the country to this day. Manuel Vargas was on leave from Rollins at the time of our trip, serving in the Dominican administration in a Cabinet-level position. Pedro Bernal, another colleague, visits the island each summer and has taken students on a service-learning trip to the Dominican Republic for the past nine years. Our class was able to take advantage of both of these remarkable resources from the planning to the implementation stages.

A final condition of note is student accountability. No matter how conscientious your students, it never hurts to directly incorporate accountability into a course, from class participation to course readings. In the case of a field study, we found a daily journal to be a useful tool in this regard. Combined with daily participation, this journal served as the determining factor in the overall grade for the field study. A copy of this assignment is found in Appendix A of this paper. The assignment entailed daily notes of the speakers students heard and at least a two page analysis of the events for that day. A ten-item requirement for pictures, newspaper articles, drawings, or some other graphical representation was also included. And a ten-page, end of the trip summary analysis completed the assignment. Most students displayed remarkable diligence with this assignment, even completing aspects of it as they waited in the lobby for our group to depart for the next stop or along the van ride to our next destination.

\section{CONCLUSIONS}

To many students, their twelve-day stint in the Dominican Republic was a once-in-a-lifetime experience. Emotions ran the gamut, from eye opening to soul searching. Clearly seeing, smelling, and even tasting the culture and environment made an impression that will not soon leave these students. After leaving a baseball field in San Pedro de Macoris, the birthplace of former Chicago Cub's slugger, Sammy Sosa, one student articulated this very position, stating:

I walked away [from the baseball field at Sammy Sosa's birthplace] and got into the van wanting to always remember how I felt at that moment. $(\mathrm{CH})$

Traveling through a developing country like the Dominican Republic also sparked students to rethink their own personal lives. For instance, after visiting the Maquiteria shanty town in Santo Domingo on just our second day, one student wrote:

Experiences like the one we experienced today can really make a person re-evaluate priorities and what's really important in life. I feel so fortunate for everything and everyone in my life. I realize that I'm blessed with the amazing life opportunities and the family I was born into. (MD)

Still another student has begun to rethink at least her immediate career goals after our field study:

Speaking with them [Chad and Dorkas, two Rollins College graduates running the eco-tourism school in Neiba] has really inspired me to take a few years off before I go to law school. I really want to do something similar to what these people have done. Somehow I want to give my services to an under-privileged country. I think it will benefit the people I am serving, but even more so myself. $(\mathrm{CW})$

All told, our twelve days in the Dominican Republic were remarkably successful in meeting the threepronged objectives of the course. Yes, there were headaches and disappointments along the way, and yes there are 
aspects that we would plan differently the next time around. Yet, in the final assessment, student feedback forcefully demonstrates the extent to which our objectives were met - providing international experience, expressly tying this real world international experience to academic theory, and organizing all this around the central topic of sustainable development. For example, one student offered this assessment in her ten-page ending analysis:

When I signed up for this course, I was interested in sustainable development, but I didn't know much about it. By the end of April, I knew a fair bit about sustainable development and thought it was a good idea, but I didn't care about it. Now, at our trip's end, I both better understand and value the principles of sustainable development. Seeing the perils of life marked by extremely unsustainable development made the true value of sustainable practices and planning more clear to me than any material covered in the course. First-hand knowledge can be golden. (MC)

Students learned through mere exposure to an international experience, even when just passing through customs in Santo Domingo and dogs sniffing for money laundering in Miami. Students learned by experiencing first-hand many of the concepts and theories we had discussed in class. From overt racism to destitute poverty, time and again, student comments reflect the strong impressions here and students learned more about sustainable development itself. They gained a greater appreciation for the obstacles confronting many Dominicans in their dayto-day struggle for sustainable development. They better understood and admired the small steps that do make a difference in attempting to implement this goal of sustainable development, from the Centro ILAC water purification program in Comedero Abajo to the eco-tourism school teaching English and computer literacy in Neiba.

The central lesson we as professors learned was that organization and flexibility must go hand-in-hand when taking students on such an environmental field study abroad. This is true in any classroom setting, of course, but it is amplified all the more when out in the field, from planning to implementation stages. One must be prepared for contingencies, such as our roadside accident in Samana or encountering a closed Haitian border due to an election-day holiday in the Dominican Republic, despite earlier information to the contrary. That said, seven additional conditions increase the likelihood for a successful field study abroad. These include student caliber, student language capabilities, institutional mechanisms within the college itself, linkage or co-requisite status of the field study with another traditional course, contacts within the country being visited, student accountability, and just plain luck. Weaving through each of these characteristics, though, is the age-old advice for any instructor, that one should be both well organized and flexible at the same time. Traveling with college students, moreover, traveling in the developing world with college students, demands it.

\section{AUTHOR INFORMATION}

Michael M. Gunter, Jr. is author of "Teaching with Case Studies: Bringing Practical Relevance to Political Theories," in Teaching Theory and Academic Writing as well as Building the Next Ark and a number of articles, reviews, and editorials that target climate change, sustainable development, and non-governmental organizations. Named a Cornell Distinguished Faculty member at Rollins College, he has led student field studies in the Bahamas and Dominican Republic as well as assisted on field study trips to Australia, Ecuador, Singapore, and Vietnam. Gunter also has extensive experience teaching international students after serving as distinguished Fulbright Scholar in the Slovak Republic in 2007.

\section{REFERENCES}

1. $\quad$ Alvarez, Julia. (1995). In the Time of the Butterflies. New York: Plume.

2. $\quad$ Dominguez, Jorge I., Robert A. Pastor, and R. Delisle Worrell (Eds.) (1993). Democracy in the

Caribbean: Political, Economic, and Social Perspectives. Baltimore: The Johns Hopkins University Press.

3. $\quad$ Elliott, Jennifer. (1999). An Introduction to Sustainable Development. NY: Routledge.

4. $\quad$ Hartlyn, Jonathan. (1998). The Struggle for Democratic Politics in the Dominican Republic. Chapel Hill: The University of North Carolina Press.

5. Honey, Martha S. “Treading Lightly? Eco-tourism's Impact on the Environment," Environment, 41(5) (June 1999), 4-9, 28-33. 
6. Howard, David. (2001). Colouring the Nation: Race and Ethnicity in the Dominican Republic. Oxford: Lynne Rienner Publishers.

7. Howard, David. (1999). Dominican Republic In Focus: A Guide to the People, Politics and Culture. New York: Interlink Books.

8. Itzigsohn, Jose. (2000). Developing Poverty: The State, Labor Market Deregulation \& the Informal Economy in Costa Rica and the Dominican Republic. University Park, PA: Penn State University Press.

9. Jayvo Designs. "The Story of Larimar." 7 Oct. 2002 <http://www.jayvodesigns.com/larimar/story.htm>.

10. Pattullo, Polly. (1999). Last Resorts: The Cost of Tourism in the Caribbean. London: Cassell.

11. Pessar, Patricia R. (1995). A Visa for a Dream: Dominicans in the United States. Boston: Allyn and Bacon.

12. Pons, Frank Moya. (1998). The Dominican Republic: A National History. Princeton, NJ: Markus Wiener Publishers.

13. Rollins College. "Sustainable Development and Transnational Corporations: A New Program at Rollins." 1 July $2002<$ http://www.Rollins.edu/susdev/desc.html $>$.

14. United States Department of State. "Background Notes: Dominican Republic" 17 July 2002 <http://www.state.gov/r/pa/ei/bgn/4153.htm $>$.

15. World Commission on Environment and Development. (1987). Our Common Future. Oxford: Oxford University Press.

16. Wucker, Michele. (2000). Why the Cocks Fight: Dominicans, Haitians, and the Struggle for Hispaniola. New York: Hill and Wang. 


\section{APPENDIX A}

\section{POL 310F - Field Study Journal Assignment}

This field study journal requires writing while we are in the Dominican Republic and a critical summary once we return to the United States. It is due Friday, May $31^{\text {st }}$ with no exceptions. We suggest you devote about a $1 / 2$ hour during the day to completing a journal entry. You will be judged on the strength of your critical analysis, creativity, and technical style (grammar, spelling, etc. - all of which you will be able to proofread when we return to the US). It is our intention that you treat this as both a serious academic reflection and an enjoyable experience. Have fun with this. Be creative and think about connections from previous talks, tours, or interesting scenes you saw on your own. And be diligent about keeping up with your daily assignment. Satisfactory completion of the journal component is required for you to pass the entire course. The following are strict requirements. Deviation from any of these requirements will result in a letter grade penalty. Each of the five main components is outlined below:

1. Notes from each lecture or tour, including the date, name, title of presenter, and location of the event. A rough guideline to apply here is 2 pages a day in your journal.

2. At least an additional 2 written pages per day while we are in the Dominican Republic. These pages should be devoted to critical analysis of the events of the day and our class focus on sustainable development. As such they will obviously include factual material. These pages are, however, much more than a summary of the events of that day. Your focus should be on analysis of these events.

3. Over the course of the 12 days we are in the Dominican you will hopefully be inspired in a non-written word manner too. Perhaps there is a drawing or sketch you would like to enter into the journal. Perhaps you would like to insert and explain a newspaper clipping or photo or even a photo of your own once we return to the US. Perhaps a graph or chart or cartoon would illustrate a point you would like to make. Your journal should include 10 total such entries.

4. Upon returning and/or while in route back to the United States you must write a 10-page critical summary of the trip. This will bring your total written pages (not including notes and visual material) to at least 34 pages.

5. All this must be in the Marble Cover Journal shown to you in class. This includes 80 college-ruled sheets and is offered at our bookstore for $\$ 2.99$. It is easy to handle and will enable the professors to standardize the page writing assignments. No other journal formats will be accepted. 